\title{
Understanding Ambulatory Blood Pressure Monitoring
}

\author{
Ankush Sachdeva ${ }^{1, *}$, Shreya Ohri ${ }^{2}$ \\ ${ }^{1}$ FNIC (Associate Consultant Cardiology)-Fortis Escorts Heart Institute, Okhla, New Delhi, India \\ ${ }^{2}$ First Cardiology Clinic, University Hospital 'Dr G. Stranski’ Pleven, Street Georgi Kochev 8A, Pleven 5800, Bulgaria
}

Email address:

ankushsachdeva0@gmail.com (A.Sachdeva)

To cite this article:

Ankush Sachdeva, Shreya Ohri. Understanding Ambulatory Blood Pressure Monitoring. International Journal of Clinical and Experimental Medical Sciences. Vol. 1, No. 1, 2015, pp. 1-3. doi: 10.11648/j.ijcems.20150101.11

\begin{abstract}
Ambulatory blood pressure monitoring (ABPM) is a unique method of measuring a 24-hour blood pressure (BP) which gives a detailed picture of daytime awake and nighttime asleep blood pressure. It should become a part of routine clinical examination as conventional BP monitoring cannot take into account certain problems like difference in BP at home and at the physician's office (white coat hypertension), excess of drug causing symptoms and profile of the drug over 24 hours. Thus, ambulatory blood pressure monitoring helps to choose a better anti-hypertensive drug best suited for the patient.
\end{abstract}

Keywords: Ambulatory, Blood Pressure, Hypertension

\section{Introduction}

Ambulatory blood pressure monitoring can be measured by using a small device which can be worn by the patient underneath the clothes which records BP measurements over 24 to 48 hours usually every 15 to 20 minutes during daytime and every 30 to 60 minutes during sleep. These recordings can be determined from the data by using a computer. The understanding of various terminologies like white coat hypertension, masked hypertension, nocturnal phenomena and resistant hypertension etc. gives better insight to the practicing clinician for individualizing the patient management. To identify people who have high BP in office but normal BP in routine outside during routine activities makes white coat hypertension, the most established indication for ABPM. Traditional definition of white coat hypertension is based on $\geq 140 \mathrm{~mm} \mathrm{Hg}$ systolic and/or $\geq 90$ $\mathrm{mmHg}$ diastolic with a mean awake ambulatory systolic/diastolic $\mathrm{BP}<135$ and $<85 \mathrm{mmHg}$. The diagnosis of white coat hypertension should be confirmed in 3 to 6 months and best followed by yearly ABPM or home BP monitoring. ${ }^{1}$ Presence of a normal office BP $<140 / 90 \mathrm{mmHg}$ with elevated daytime $\mathrm{BP}$ on $\mathrm{ABPM}(\geq 135 / 85 \mathrm{mmHg})$ or home $\mathrm{BP} \geq 135 / 85 \mathrm{mmHg}$ is the usual definition of masked hypertension. As with white coat hypertension, the definition needs to be extended to 24 hours $\mathrm{BP}>130 / 80 \mathrm{mmHg}$ and the patients on medication have to be excluded is suggested as they are already diagnosed cases of hypertension. The 2013 ESH (European Society of Hypertension) recommended ABPM in all subjects with high normal office BP or normal office BP with asymptomatic organ damage or high cardiovascular risk. $^{2}$

The term nocturnal phenomenon pertains to the BP pattern during sleep whether it raises, falls or remains constant. The entire BP recordings for 24 hours are evaluated. The BP generally reaches a basal level during sleep. Various patterns of nocturnal BP have been identified; the nocturnal decline may just be missing (non-dipping), it may even rise (reverse dipping) or sometimes there may be extreme dipping and the morning BP surge after dipping helps to prognosticate the case. The general consensus is that a nocturnal fall $>10 \%$ of day time values and a night/day BP ratio $>0.9$ is to be used as to define as dippers.

\section{Interpreting ABPM Report}

Ambulatory blood pressure monitor uses oscillometric method of measuring BP. It provides the total recording time in hours and minutes, the duration of daytime and nighttime record, average systolic/diastolic BP in $\mathrm{mmHg}$. The dataset consists of a full record of the systolic/diastolic BP along with time, heart rate and mean $\mathrm{BP}$ readings. It gives the average day and night time measurements along with the average difference in day/night time systolic/diastolic BP. The maximum and minimum BP with time and an average of above recordings are graphically represented.

\section{Recommended Size for ABPM Cuff}

The recommended sizes for ABPM cuff are as follows: ${ }^{3}$ 
Table 1. Showing the recommended cuff size for ABPM.

\begin{tabular}{ll}
\hline Child & $12 \times 18 \mathrm{~cm}$ \\
Adult & $12 \times 26 \mathrm{~cm}$ \\
Large arm width adult & $12 \times 40 \mathrm{~cm}$ \\
\hline
\end{tabular}

ABPM: Ambulatory blood pressure monitoring

\section{Clinical Indications for ABPM}

ABPM is useful in excluding white coat hypertension, helps to identify nocturnal hypertension, ${ }^{4}$ to know the profile of the drug over 24-hour, to decide drug of choice in elderly patients, in diagnosing hypertension in pregnant females ${ }^{5}$ and in cases of resistant hypertension and helps to detect episodes of hypotension, if taking place. The main indications as per ESH/ESC guidelines can be summarized as follows in table 2.

Table 2. Specific indications for ABPM.

Marked discordance between office BP
Assessment of dipping BP
Suspicion of nocturnal hypertension or absence of dipping, such as patients
with sleep apnea, CKD or diabetes
Assessment of BP variability

CKD: Chronic kidney disease, ABPM: Ambulatory blood pressure monitoring

\section{Instruction to the Patient}

The patient is made to relax in a quiet room, the patient's details like name and identification number is entered in the monitor. The BP in both arms is measured and if the difference in both arms is $<10 \mathrm{~mm} \mathrm{Hg}$, then the nondominant arm is used and if $\geq 10 \mathrm{~mm} \mathrm{Hg}$, then the arm with higher pressure is used for ABPM. The correct cuff size is then chosen and the frequency of BP monitoring is set. Patient is explained about the number of times the cuff will inflate and deflate and patient is asked to maintain a record of their activity during BP measurements, to note down the time they had their antihypertensive medicine and time at which they go to bed and wake up and also to note down if they had any kind of symptoms. The display should normally be switched off to avoid anxiety and distraction to the patient.

\section{Data Analysis}

It is mandatory that the ABPM measures more than 14 day-time systolic and diastolic BP measurements and more than 7 night-time systolic and diastolic measurements for correct analysis. Statistics include the heart rate; mean day and night time systolic and diastolic BP measurements. There has been controversy over what should be regarded as normal or abnormal BP by ABPM. ${ }^{6}$ Also, lower BP may be abnormal in a patient with high risk profile and also depending upon the underlying disease process. ${ }^{7}$ The recent NICE guidelines, the JNC 7, ESH/ESC guidelines for 2013, such as IDACO (International Database on Ambulatory blood pressure monitoring in relation to Cardiovascular Outcomes Investigators) and Ohasama summarised the thresholds for hypertension diagnosis based on ABPM as described in the table $3 .^{8}$

Table 3. Recommendations for normal and abnormal BP for ABPM.

\begin{tabular}{ll}
\hline 24-hour average & $\geq 130 / 80 \mathrm{mmHg}$ \\
Awake (day-time) average & $\geq 135 / 85 \mathrm{mmHg}$ \\
Asleep (night-time) average & $\geq 120 / 70 \mathrm{mmHg}$ \\
\hline
\end{tabular}

ABPM: Ambulatory blood pressure monitoring

Therfore, further studies are needed to define thresholds precisely specially in high risk patients.

\section{Conclusion}

AS per the ESH/ESC guidelines 2013, it has been advised to use the non-dominant arm, for 24-25 hours duration .It was recommended that the measurements are made at same frequency during the day and the night and excessive intervals between BP readings should be avoided as they reduce the accuracy. ${ }^{9}$ Several prognostic significance of ABPM has been observed and it has been shown that left ventricular hypertrophy $(\mathrm{LVH})$ and carotid intima- media thickness (CIMT) are better correlated with ABPM than with office blood pressure. ${ }^{10}$ The presence of diabetes mellitus and history of cardiovascular disease, resistant hypertension and target organ damage are the settings which require a frequent ABPM.

\section{References}

[1] Pickering TG, James GD, Boddie C, Harshfield GA, Blank S, Laragh JH .How common is white coat hypertension? JAMA.1988; 259:225-228.

[2] Mancia G, Fagard R, Narkiewicz K,etal;List of authors Task Force Members .2013 ESH/ESC Guidelines for the management of arterial hypertension:The Task Force for the management of arterial Hypertension :The task force management of arterial hypertension of the Europeon Society of Hypertension (ESH) and Europeon society of Cardiology (ESC).Hypertens.2013;31:1281-1357.

[3] Shekelle PG, Woolf SH, Eccles M, Grimshaw J. Clinical guidelines: developing guidelines.BMJ.1999; 318:593-596.

[4] O’Brien E, Sheridan J, O’Malley K. Dippers and non-dippers (letter) Lancet.1988; ii: 397.

[5] Bellomo G, Narducci PL, Rondoni F, Pastorelli G ,Stagnoni G, Angeli G,et al. Prognostic value of 24-hour blood pressure in pregnancy.JAMA .1999;282:1447-1452.

[6] O’Brien E, Owens P, Staessen J, Imai Y, Kawasaki T, KuwajimaI. What are the normal levels for ambulatory blood pressure measurement? Blood press monitoring.1998; 3:131-132.

[7] Ramsay LE, Williams B,Johnston GD, MacGregor GA, Poston L, Potter JF,et al. Guidelines for management of hypertension: report of third working party of British Hypertension Society. J Hum Hypertens. 1999; 13:569-592.

[8] Ohkubo T, Imai Y, Tsuji I, Naga I K, Ito S, Satoh H, Hisamichi S, Reference values for 24-hour ambulatory blood pressure monitoring based on prognostic criterion: the Ohasama Study. Hypertension .1998; 32:255-259. 
[9] Di Rienzo M, Grassi G, Pedotti A, Mancia G. Continuous vs intermittent blood pressure measurements in estimating 24hour average blood pressure. Hypertension 1983; 5:264-269.
[10] Gaborieau V, Delarche N,Gosse P. Ambulatory blood pressure monitoring vs. self-measurement of blood pressure at home: correlation with target organ damage. J Hypertens 2012; 30:1289-1299. 